\title{
COLOUR PRODUCTION AND STABILITY IN THE FOLIN AND WU METHOD OF BLOOD GLUCOSE ESTIMATION
}

\author{
BY \\ STANLEY DISCHE \\ From the Royal Air Force Institute of Pathology and Tropical Medicine, Halton, Aylesbury, \\ Buckinghamshire
}

(RECEIVED FOR PUBLICATION OCTOBER 21, 1954)

The methods most commonly employed for the estimation of blood glucose are dependent upon the ability of glucose to reduce alkaline copper solutions. Reagents containing phosphomolybdic acid are then frequently used to form a blue complex by combination with the reduced copper. All these methods suffer the disadvantage that the final colour fades at such a rate as to imperil its accurate comparison with a standard glucose solution similarly treated.

Fading was neither very apparent nor of much importance when visual colorimeters were employed with direct comparison of standard and unknown colours. Folin (1929) first recorded the existence of fading and described a method to combat it. Interest was aroused by the general adoption of the photoelectric colorimeter, and many technical modifications were introduced to circumvent fading. These were remarkable for their variety rather than for their success in routine use.

In the present investigation the factors influencing fading have been determined and a new modification of the Folin and $\mathrm{Wu}$ technique has been evolved which simplifies the standard technique at the same time as it eliminates fading. Although the Folin and Wu (1920) method was chosen for this investigation the principles involved are applicable to other methods of blood glucose estimation in which similar reagents are used.

\section{Reagents and Apparatus}

Analar grade materials were used in the preparation of all reagents.

Copper Reagent.-This was made up as described by Folin and Wu (1920) but stored as two solutions as recommended by Folin (1929). Copper reagent was freshly prepared from the two constituent solutions each day.
Phosphomolybdic Reagent (P.M.R.).-This reagent was also prepared as described by Folin and Wu (1920).

Standard Glucose Solution.-This contained $2.5 \mathrm{mg}$. glucose per $100 \mathrm{ml}$. in saturated benzoic acid.

Standard Folin and Wu tubes of bulb capacity $4 \mathrm{ml}$., a special Folin and Wu tube of bulb capacity $20 \mathrm{ml}$., an E.E.L. portable photoelectric colorimeter, and a set of "large" colorimeter tubes were required.

\section{The Effect of Dilution upon Colour Stability}

Experiment 1 : Stability of Colour of Undiluted Mixture.-Previous workers (Folin, 1929; Lehmann and Silk, 1952) have noted that the amount and rate of fading are increased when the reduced copper-P.M.R. mixture is diluted with water. Fading of the undiluted mixture was compared with that found in an identical sample diluted with distilled water.

Technique.-Copper reagent, $10 \mathrm{ml}$., and $10 \mathrm{ml}$. of standard glucose solution were mixed in the special Folin and $\mathrm{Wu}$ tube. The tube was stoppered with non-absorbent cotton wool and heated in a boiling water-bath for exactly six minutes. The tube was immediately cooled to room temperature and after three minutes had elapsed $10 \mathrm{ml}$. of P.M.R. added. After a further two minutes the contents of the tube were thoroughly mixed and as much $\mathrm{CO}_{2}$ as possible removed by agitation (one minute), then $3 \mathrm{ml}$. was pipetted into a large E.E.L. colorimeter tube containing $6 \mathrm{ml}$. of distilled water. The contents of the tube were thoroughly mixed and read in the colorimeter at 1, 10, 30,60 minutes and 2, 4, and 22 hours after dilution. The density of the undiluted mixture was determined at similar times by making a fresh 1 in 3 dilution on each occasion with immediate mixing and reading. The colorimeter tubes were tightly stoppered with cotton wool and stored in the dark between reading, as was the large Folin and Wu tube. Environmental temperature was kept as constant as possible. The constancy of the colorimeter was 
checked using a neutral grey solution giving a colorimeter reading similar to that of the solutions under test.

Fig. 1 illustrates the results obtained and shows that fading of the undiluted mixture was much less than that which followed dilution with distilled water.

Experiment 2 : Dilutions of P.M.R. as Diluting Agent instead of Distilled Water.-Four dilutions of P.M.R. were prepared: $\frac{1}{6}, \frac{1}{3}, \frac{1}{2}, \frac{2}{3}$ strength in distilled water. These were used as diluting agents and fading compared with that found when distilled water was used for this purpose. The fading of the undiluted mixture was also determined.

Technique.-This was as described above, and $3 \mathrm{ml}$. quantities of the reduced copper-P.M.R. mixture were dispensed into a series of colorimeter tubes each containing $6 \mathrm{ml}$. of the diluents under test.

The results are shown in Fig. 2. The fading seen with $\frac{1}{3}$ strength P.M.R. as diluent was very similar to that of the undiluted mixture. The fading seen with $\frac{1}{6}$ strength P.M.R. was intermediate between $\frac{1}{3}$ strength and distilled water.

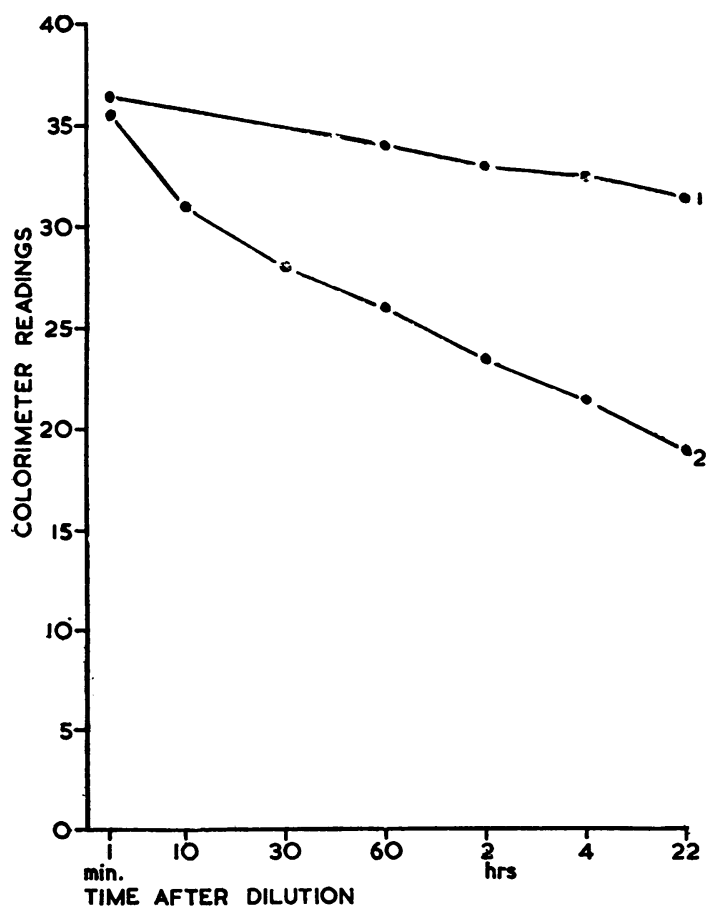

FIG. 1.-Stability of colour of undiluted reduced copper-phosphomolybdic reagent mixture. Change in colour density of " undiluted mixture" (1) compared with that on dilution with distilled water (2).
Increased density of colour occurred with $\frac{1}{2}$ and $\frac{2}{3}$ strength reagent up to four hours, after which $\underset{\vec{\rho}}{\vec{F}}$ there was a slight decrease.

Experiment 3: Dilute Phosphoric Acid as Diluting Agent in Place of Distilled Water.-Leh- $\frac{\bar{\sigma}}{\partial}$ mann and Silk (1952) have suggested that it is the $\stackrel{\mathscr{\complement}}{\complement}$ alteration in phosphoric acid concentration wh:ch is responsible for fading on dilution. We have $\overrightarrow{0}$ used as diluting agent dilutions of phosphoric acid equal to those found in the dilutions of P.M.R. $\vec{\omega}$ used above.

Technique.-Dilutions of phosphoric acid contain- $\frac{\overline{0}}{0}$ ing $4.0,8.0,12.5$, and $16.5 \% \mathrm{v} / \mathrm{v}$ of acid in distilled $\%$ water were prepared and used in an identical manner $\omega$ to that described above.

The results shown in Fig. 3 are markedly 0 different from those in Fig. 2. Fading was quite considerable with lower concentrations of acid $\vec{\square}$ and higher ones apparently caused a rapid immediate loss of colour. No concentration caused $\stackrel{\odot}{\mathscr{C}}$ any increase in density of colour.

Experiment 4 : Initial Addition of P.M.R. Made $\vec{f}$ in Diluted Form.-Since the degree of fading

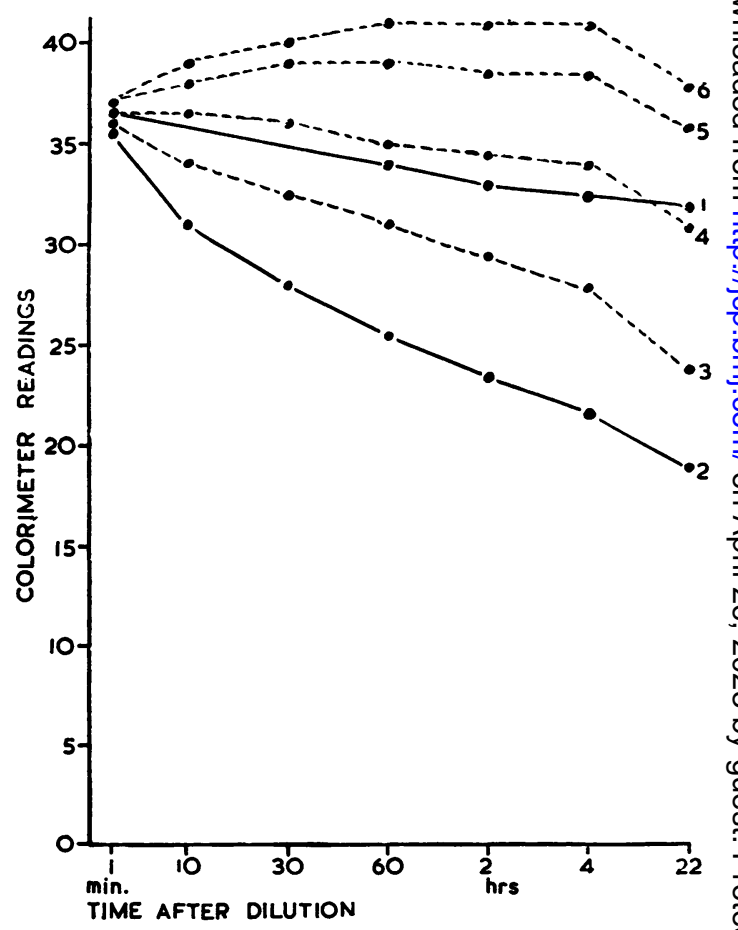

FIG. 2.-Dilutions of phosphomolybdic reagent as diluting agent in place of distilled water. Change in colour density of undiluted mixture (1) and that diluted with distilled water (2) compared
with changes found when $\frac{1}{8}$ strength (3), $\frac{1}{3}$ strength (4), $\frac{1}{2}$ strength (5), and $\frac{2}{3}$ strength (6) reagent are used as diluents. 


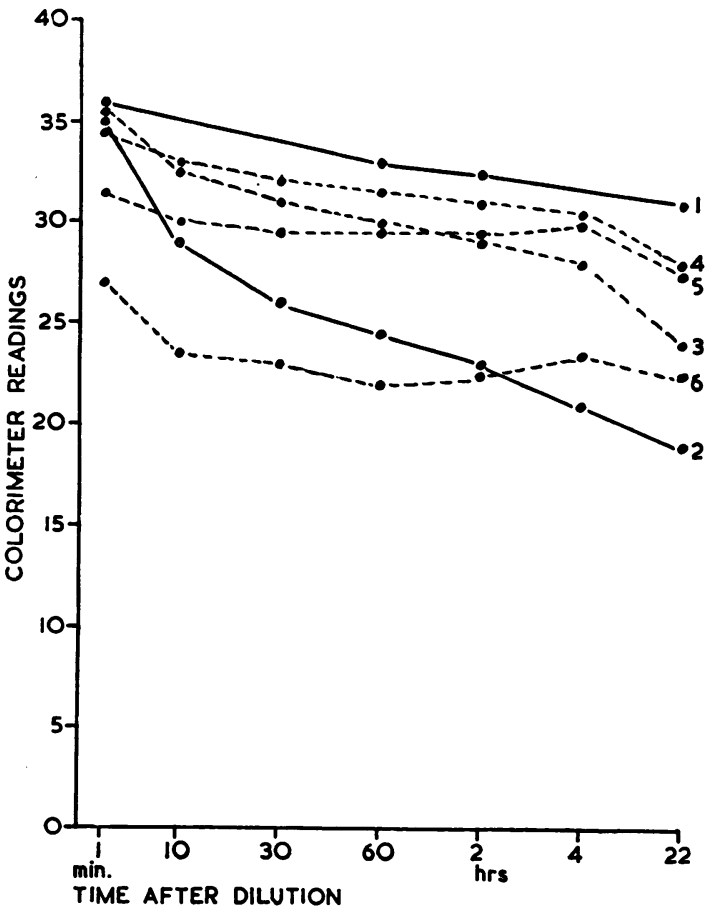

FIG. 3.-Dilute phosphoric acid as diluting agent in place of distilled water. Change in density of undiluted mixture (1) and that diluted with distilled water (2) compared with changes found wien $4 \%(3), 8 \%(4), 12.5 \%(5)$, and $16.5 \%(6) v / v$ of phosphoric acid are used as diluents.

seemed related to change in the concentration of the P.M.R. reagent the effect was determined of using the reagent already diluted.

Technique.-Dilutions of P.M.R. were prepared in distilled water, their strength ranging from $7 \%$ to $100 \%$. Copper reagent, $2 \mathrm{ml}$., and $2 \mathrm{ml}$. of standard glucose solution were dispensed into a series of standard Folin and Wu tubes. After the contents had been mixed the tubes were stoppered with nonabsorbent cotton wool and heated together in a boiling water-bath for exactly six minutes. After cooling to room temperature, the P.M.R. was added as a $14 \mathrm{ml}$. quantity of one of the dilutions, a different strength being used for each tube. After one minute the contents of the tubes were mixed and readings determined at times similar to those employed in the previous experiments, but, as changes detected in the first five minutes were minimal, first readings were made at four minutes for technical convenience.

The results are illustrated in Fig. 4. The uppermost point at each dilution represents density of colour at four minutes and the lowermost density at 22 hours. The line joining them represents fading during that period. It will be seen that as the concentration of P.M.R. increased so did

\begin{tabular}{|c|c|c|c|c|}
\hline \multirow{4}{*}{$\begin{array}{c}\text { Final } \\
\text { Concen- } \\
\text { tration } \\
\text { of } \\
\text { Reagent } \\
(\%)\end{array}$} & \multicolumn{2}{|c|}{$\begin{array}{l}\text { Experiment } 2 \\
\text { (Reagent Added } \\
\text { in Two Stages) }\end{array}$} & \multicolumn{2}{|c|}{$\begin{array}{c}\text { Experiment } 4 \\
\text { (Reagent Added } \\
\text { in One Stage) }\end{array}$} \\
\hline & \multicolumn{2}{|c|}{$\begin{array}{c}\text { Concentration after 1st } \\
\text { Addition 33\% }\end{array}$} & & \\
\hline & \multicolumn{2}{|c|}{ Time after 2 nd Addition } & \multicolumn{2}{|c|}{ Time after Addition } \\
\hline & $1 \mathrm{~min}$. & $22 \mathrm{hr}$. & $4 \mathrm{~min}$. & $22 \mathrm{hr}$. \\
\hline $\begin{array}{l}11 \\
22 \\
33 \\
44 \\
55\end{array}$ & $\begin{array}{l}35 \cdot 5 \\
36 \\
36 \cdot 5 \\
37 \\
37\end{array}$ & $\begin{array}{l}19 \\
24 \\
31 \\
36 \\
38\end{array}$ & $\begin{array}{l}25 \cdot 5 \\
30 \\
34 \\
39 \\
41 \cdot 5\end{array}$ & $\begin{array}{l}18 \cdot 5 \\
24 \\
31 \cdot 5 \\
37 \cdot 5 \\
37 \cdot 5\end{array}$ \\
\hline
\end{tabular}

the density of colour up to a maximum at about $60 \%$ final concentration; beyond this there was a fall. The amount of fading decreased up to $40 \%$ final concentration after which it increased again.

Experimental conditions were so arranged that the final concentration of reduced copper was exactiy similar to that in Experiment 2 when the P.M.R. was added in two stages-first undiluted and second in diluted form. The table shows that

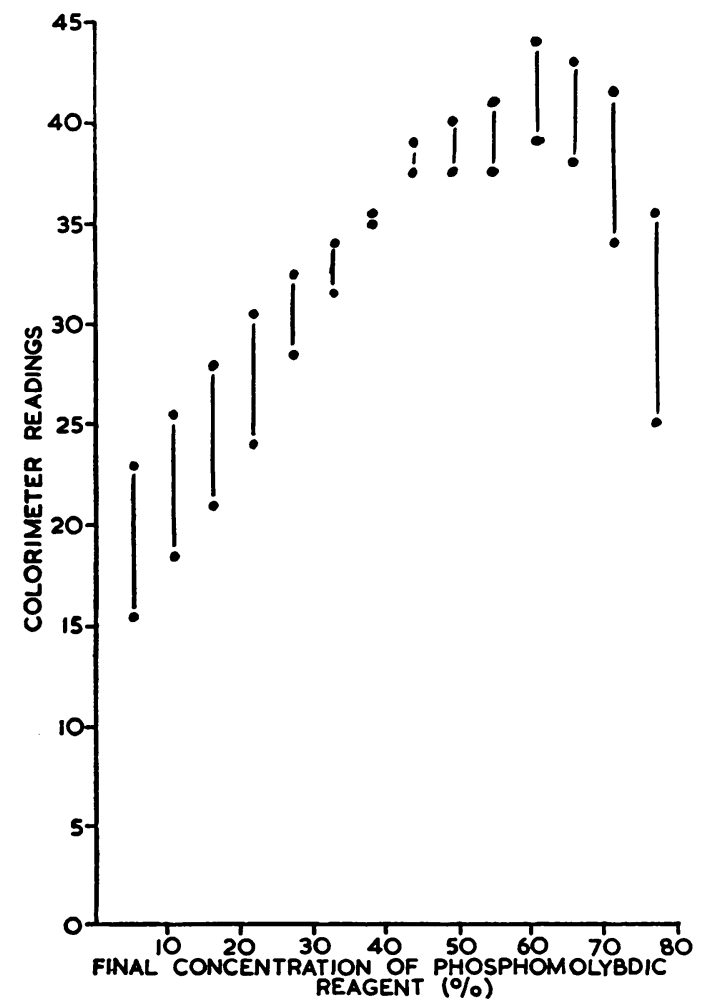

FIG. 4.-Addition of phosphomolybdic reagent made in diluted form. Reagent added as a $14 \mathrm{ml}$. quantity of a dilution in distilled water. At each concentration the upper point represents colour density at 4 minutes after addition of reagent and lower point density at 22 hours. 
at 22 hours mixtures similar in final concentration of P.M.R. reached similar values in both experiments.

Discussion.- - It is apparent that in the Folin and $\mathrm{Wu}$ method the density of colour produced is dependent not only upon the concentration of reduced copper but also upon that of the P.M.R. The fading which follows dilution with distilled water is due to change in the concentration of P.M.R.

Although the addition of reagent to reduced copper results in an immediate production of colour, any change of concentration of P.M.R. is followed by a slow change in density of colour until a new equilibrium is reached. The rapidity of this change varies directly as the difference between old and new densities.

Further experiments revealed a tendency for very high concentration of P.M.R. to retard the original production of colour. The slight fading which occurs with constant concentration of P.M.R. seems influenced by the absolute concentration of the reagent. It is likely that this is related to slight changes in the acidity of the final

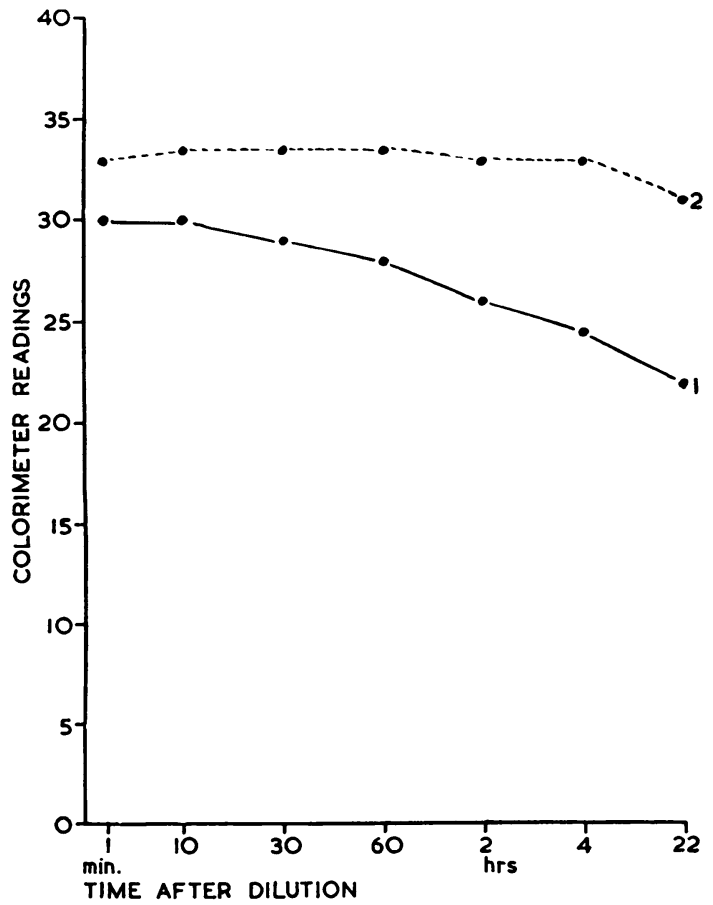

FIG. 5.-The effect upon colour stability of a small increase in phosphoric acid concentration in a dilute phosphomolybdic reagent. Change in colour density following the addition of $14 \mathrm{ml}$. of $16.5 \%$ reagent (1) compared with that found with use of a similar reagent in which the phosphoric acid concentration has been raised by $2.5 \%(2)$.

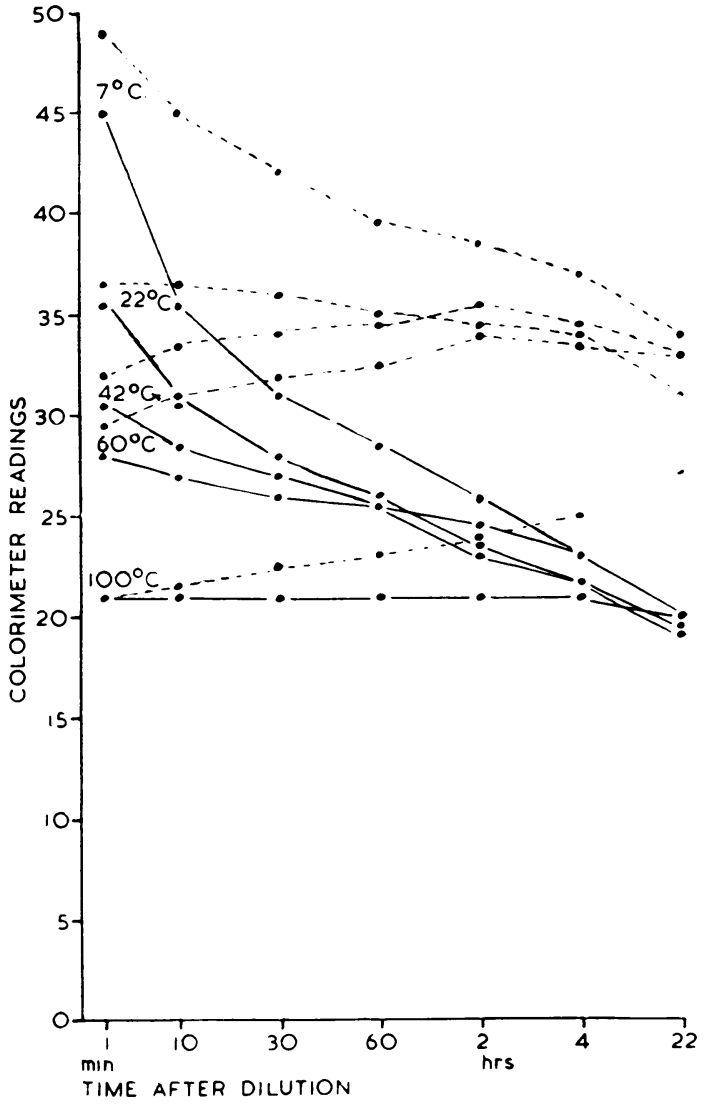

Fig. 6.-The effect of temperature uren colour prcciuction and stability. Reduced copper-phosphomolybdic reaction initiated and maintained for two minutes at five different temperatures before dilution with distilled water (continuous lines) and with $\frac{1}{3}$ strength reagent (intermittent lines).

solution because increasing quantities of acid P.M.R. are added to a fixed quantity of alkaline copper solution. This fading can be largely inhibited by adjustment of acidity (Fig. 5).

\section{Effect of Temperature upon Colour Production and Stability}

Several of the more successful modifications introduced to prevent fading involve raising the temperature of the reduced copper-P.M.R. reaction. The effect of temperature on this reaction was determined over a full range.

Technique.-The large Folin and $\mathrm{Wu}$ tube was employed in the manner already described, but after the six minutes' boiling the reduced copper was brought immediately to the temperature required and $10 \mathrm{ml}$. of P.M.R., already warmed or cooled, was added. The temperature was maintained for two 
minutes and, after thorough mixing, dilutions made with distilled water and $\frac{1}{3}$ strength P.M.R., both at room temperature, and colour densities followed.

Fig. 6 illustrates the results. Initial colour production varied inversely as the temperature. Intensity of colour at $7^{\circ} \mathrm{C}$. was more than twice that at $100^{\circ} \mathrm{C}$. Those reduced copper-P.M.R. mixtures diluted with distilled water all arrived at similar densities at 22 hours; those diluted with $\frac{1}{3}$ strength P.M.R. tended to do the same.

Further dilutions with $\frac{1}{6}, \frac{1}{2}$, and $\frac{2}{3}$ strength P.M.R. were made with the mixture maintained for two minutes at $100^{\circ} \mathrm{C}$., and Fig. 7 illustrates the results. All dilutions, except that with distilled water, increased in density of colour ; the increase varied directly as the concentration of P.M.R. One-third strength P.M.R. and the undiluted sample showed similar curves.

Discussion.- In the Folin and $\mathrm{Wu}$ method temperature has a profound influence upon colour production and stability. The density of colour produced varies inversely as the temperature at which the reaction takes place. Any subsequent change in temperature results in a gradual change in density of colour to reach a new equilibrium.

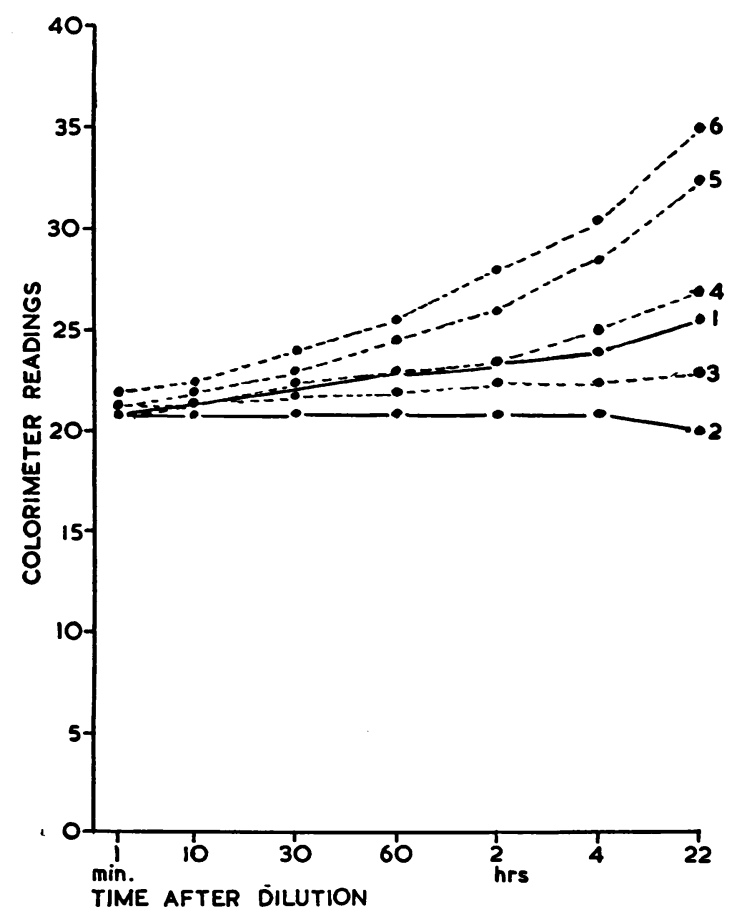

FIG. 7.-Reduced copper-phosphomolybdic reaction initiated at $100^{\circ} \mathrm{C}$. and dilutions made in various strength of phosphomolybdic reagent. Change in density of undiluted mixture (1), diluted with distilled water (2), diluted with $\frac{1}{8}$ strength (3), $\frac{1}{3}$ strength (4), $\frac{1}{2}$ strength (5), $\frac{1}{3}$ strength (6) phosphomolybdic reagent.

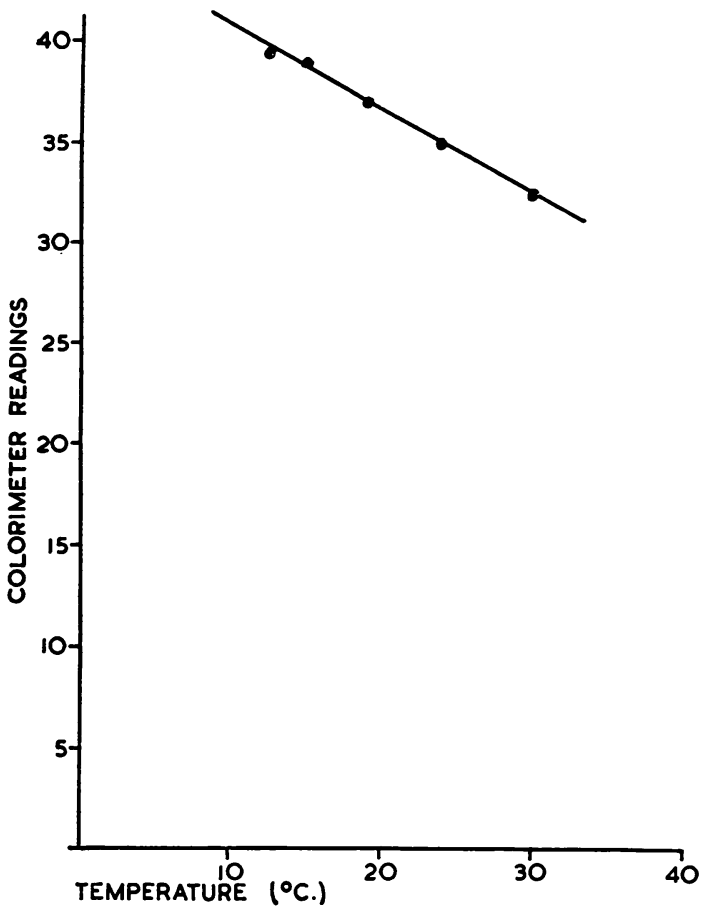

FIG. 8.-Colour density and environmental temperature. Variation in colour density encountered with a single standard glucose solution when the reduced copper-phosphomolybdic reaction is performed at different temperatures.

In these experiments the effect of temperature upon colour stability has to be distinguished from that of change in concentration of P.M.R. Also, the slight fading which occurs independently of these factors must be considered. The curve given by the reduced copper-P.M.R. mixture initiated at $7^{\circ} \mathrm{C}$. and diluted with distilled water represents all factors favouring fading. The stability of colour in that mixture initiated at $100^{\circ} \mathrm{C}$. and diluted with distilled water results from opposition of the two main factors.

When employing the classic Folin and Wu technique, the density of colour produced by a standard solution can be expected to vary from day to day, and from season to season with the environmental temperature. Fig. 8 illustrates the range to be expected.

Reduced copper solutions should not be cooled to below room temperatures by using running tap water (which in our laboratory is $10^{\circ} \mathrm{C}$. below room temperature). The initial temperature of the reduced copper-P.M.R. mixture is largely that of the reduced copper, and so after dilution the initial colour fades at an even faster rate, for fading due to a rise of room temperature is added to that due 
to a change in P.M.R. concentration. Also, with such supercooling, it is difficult to be certain that test and standard solutions are at exactly the same temperature when P.M.R. is added.

\section{Photosensitivity of Reduced Copper-P.M.R. Mixture}

Using the Folin and Wu method considerable variation in result was encountered when identical experiments were performed at different times of day. These variations were found to be due to a non-specific increase in density of colour which occurs on exposures of the reduced copperP.M.R. mixture to sunlight.

Technique.-Standard glucose solution and a distilled water blank were treated with alkaline copper reagent using the classic Folin and $\mathrm{Wu}$ technique, but the P.M.R. was added in diluted form. A $14 \mathrm{ml}$. quantity was employed, consisting of $3 \mathrm{ml}$. P.M.R., $2 \mathrm{ml}$. of $25 \%$ phosphoric acid, $9 \mathrm{ml}$. distilled water. Each of the final solutions was dispensed into a pair of colorimeter tubes. One of each pair was placed close to a window on a sunny day but shielded from

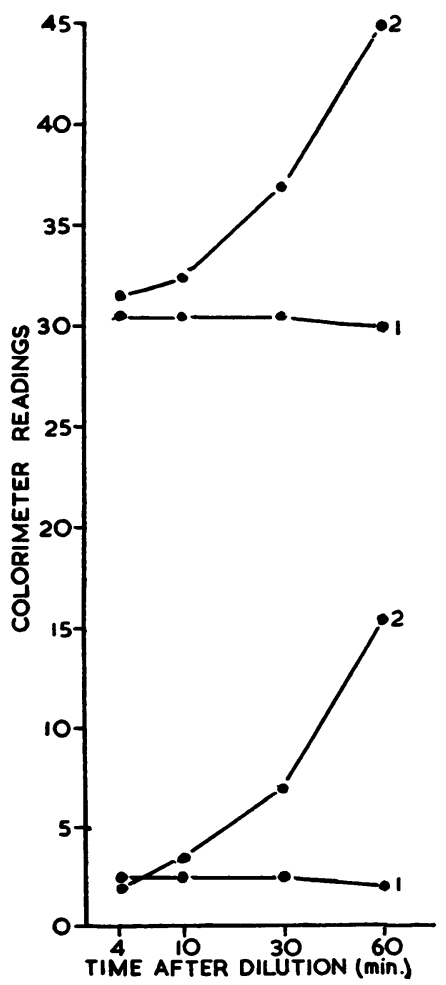

Fig. 9.-Photosensitivity of reduced copper-phosphomolybdic reagent mixture. Identical pairs of standard (upper) and blank (lower) solutions prepared. One of each pair left in the shade (1), the others (2) placed close to a window on a sunny day but shielded from direct sunlight. Tubes in position at six minutes. direct sunlight. The remaining tubes were kept in the shade. Colour densities were determined at four, 10,30 , and 60 minutes after addition of P.M.R. Tubes were in position at six minutes.

The results are illustrated in Fig. 9. In spite of shielding from direct sunlight the increase in $\mathbb{\varnothing}$ density was marked. By 60 minutes the blank had risen from 2 to $15 \frac{1}{2}$ units and test $31 \frac{1}{2}$ to $45, \infty$ i.e., each had risen $13 \frac{1}{2}$ units. This increase is $\vec{O}$ therefore unrelated to the reduced copper present. $\overrightarrow{-}$ Exposure of the P.M.R. or copper reagent to light before mixing does not produce this colour in $\overline{-}$ crease when they are finally brought together Boiling the alkaline copper reagent has no influ-i ence upon the production of this photosensitivity, N for simple addition of P.M.R. to alkaline copper ${ }^{\omega}$ reagent results in a mixture of similar sensitivity.으

It is felt that this phenomenon must explain theincrease in density of colour of blank solutions? previously observed (King and Garner, 1947) withe alkaline copper and phosphomolybdic reagents. $\stackrel{\oplus}{+}$ Blank solutions have been kept up to three days $\overrightarrow{0}$ without any increased density of colour provided that they had been shie'ded from sunlight. A false impression of colour stability may be presented when a solution which is fading is exposed to sunlight. In practice care must be taken to avoid? sunlight causing an increased density of colour. $\frac{\circ}{\mathrm{D}}$ The danger lies in differential exposure of standard and test solutions.

Under normal laboratory conditions this presents no problem and provided the staff is aware of the danger no errors will arise. This applies to the Folin and Wu method, to all its modifications, and to methods employing similar reagents, such asothose of Benedict (1931) and Haslewood and 3 . Strookman (1939).

Purity of Sodium Carbonate and Colour Stability

Previous workers (King and Garner, 1947) have stressed the importance of using absolutely pureo samples of sodium carbonate in the preparation of alkaline copper reagents in order to prevent fading. $N$ Impure samples of carbonate have been used with- $N$ out any increase in fading being observed. AN greater reduction was noted, but this was con- $\sigma$ sidered to be due to the bicarbonate content and the lowered alkalinity which increases the power of reduction of glucose (Harding and Downs, $\infty$ 1933). Blank colours were not increased when freshly prepared reagents were used.

\section{Quantity of Reduced Copper and Colour Production and Stability}

In all the experiments so far described a single standard solution containing $2.5 \mathrm{mg}$. of glucose 
per $100 \mathrm{ml}$. was used. Experiments repeated, using stronger and weaker solutions, showed that alteration in colour density was always proportional to the initial colour developed. Folin and $\mathrm{Wu}$ and " true sugar" blood filtrates showed similar results.

Using the dilute P.M.R. in the manner already described, the standard curve shown in Fig. 10 was produced. The relationship between glucose and colour density was linear between 0.6 and $4.4 \mathrm{mg}$. glucose per $100 \mathrm{ml}$; this is equivalent to

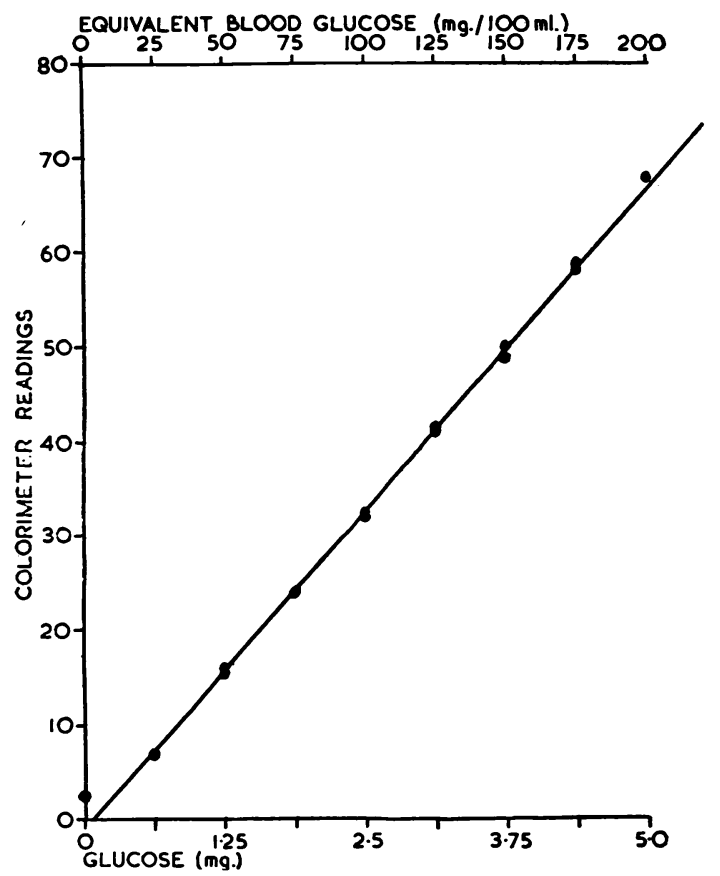

FIG. 10. - Standard curve using dilute phosphomolybdic reagent. The blood glucose equivalent assumes a dilution of 1 in 40 .

25-175 mg. of blood glucose when, in the commonly used micromethod, blood is diluted 1 in 40 .

It is apparent from the graph that a line drawn through zero and the reading of the $100 \mathrm{mg}$. standard faithfully represents the relationship between glucose and colour density in the range 25 to $175 \mathrm{mg}$. Above $175 \mathrm{mg}$. density increases out of proportion to glucose concentration.

\section{Modifications of the Folin and Wu Method}

Folin (1926 and 1929), using an increased amount of a modified P.M.R., suggests dilution with 1 in 5 strength P.M.R. to prevent fading.

This technique is largely effective in maintaining a stable colour. Using dilute reagent in place of distilled water the change in concentration of
P.M.R. is limited. This feature has been adapted for use with standard P.M.R. (War Department Technical Manual, 1946), 1 in 5 strength P.M.R. being advocated as diluent. In our hands this still leaves appreciable fading; 1 in 3 strength is more effective (Fig. 2). The modified reagent, compared with the standard one, contains approximately twice the concentration of the effective constituents. By using the equivalent of a fourfold increase in P.M.R. concentration, the factors employed by the method of Sobel (infra) also help to maintain the colour stable. This technique has not been used widely because of difficulty in preparing the reagent, and because initial colour production is slow and time must be allowed for its full development.

Fiorentino and Giannettasio (1940) heat the reduced copper-P.M.R. mixture for five minutes in a boiling water-bath before dilution and reading.

Thomson (1946) adds P.M.R. to reduced copper immediately after boiling, removing tubes one by one at 15 -second intervals and adding P.M.R. to each individually.

Fister (1950) adds sodium sulphate to the alkaline copper reagent, follows the Folin (1926 and 1929) technique, and boils for five minutes after P.M.R. is added.

Tonks (1952) adds P.M.R. to the reduced copper, which is not cooled, and boils for two minutes before diluting with distilled water.

The principal feature of these techniques is a raising of the temperature of the reduced copperP.M.R. mixture and they are successful in producing stable colours. The lowermost curves of Figs. 6 and 7 represent these modifications. The result is achieved by balancing increased density due to cooling against the decrease caused by dilution with distilled water. When the reduced copperP.M.R. mixture is diluted with distilled water the new density is almost exactly that which can be maintained at the new temperature and P.M.R. concentration. It should be noted that if the dilution is less than 1 in 3 a slight increase in density can be expected, and, if greater, then a fading will be observed. Of these methods only those of Fiorentino and Giannettasio and of Tonks are practicable. They can be criticized on two points. First, an essential feature of the Folin and $\mathrm{Wu}$ method is the accurate timing of the six minutes' heating in the boiling water-bath. This period must be exactly the same for both standard and test samples. Tonks does not cool immediately at the end of the boiling period, and he emphasizes that this must not be done. The reduction of the copper reagent must continue while the tubes are 
still hot until P.M.R. is added. If a dozen tubes are involved, then the addition of the reagent must take at least a minute, leading to a variable treatment of the tubes. Secondly these modifications involve an extra manipulation and therefore an extra opportunity for technical error.

Sahyun (1936) adds sodium sulphate to the alkaline copper reagent and allows five minutes for the reduced copper-P.M.R. reaction to take place.

The Leitz photometer handbook (as quoted by Tonks, 1952) increases to 10 minutes the time allowed for the reduced copper-P.M.R. reaction.

Tonks found the method of Sahyun to have little advantage over the traditional method. The Leitz method he found to be partially successful in retarding fading.

We have increased up to 40 minutes the time allowed for the reduced copper-P.M.R. react on with no effect upon fading when finally diluted with distilled water and do not consider these methods to be of value.

Sobel (1947) uses five times the normal amount of P.M.R. We agree with Tonks in finding such a technique successful. By increasing the quantity of P.M.R. two factors are employed. The amount of P.M.R. is large-sufficient to bring the final concentration in the reduced copper-P.M.R. mixture to beyond the peak of colour density at $60 \%$. Dilution, provided it is not great, will bring the P.M.R. consentration back to a level giving a similar colour density on the opposite side of the peak (Fig. 4). Also at high concentrations of P.M.R. the rate of initial colour production and subsequent change are slowed down, helping to keep density constant. The use of such concentrations of P.M.R. is uneconomical and inconvenient in practice.

Lehmann and Silk (1952) dilute with $11.55 \%$ $\mathrm{w} / \mathrm{v}$ phosphoric acid. They also remark upon the effect of not diluting after the addition of P.M.R. and also upon keeping final solutions in iced water.

In our hands the concentration advised gives appreciable fading. The use of a concentration of phosphoric acid equivalent to that in the undiluted mixture does retard fading, but nevertheless allows a significant amount.

The mechanism seems in the nature of a change in quality of the P.M.R. associated with an increase of phosphoric acid concentration relative to the molybdic acid. Lehmann and Silk claim that by incorporating a large quantity of phosphoric acid in the P.M.R. a similar stability can be achieved, distilled water being again used as diluent. This would be in keeping with the explanation suggested above.

The stability of the undiluted mixture has already been discussed. Storing tubes in iced 흠 water will result in the fading of dilution being $\frac{\bar{m}}{\sigma}$ apposed by the increased density caused bv lower- $\mathbb{\nabla}$ ing the temperature.

\section{A New Modification}

The investigation has led to a further modification of the Folin and Wu method. The P.M.R. is added in diluted and slightly acidified form. The working reagent is constituted-P.M.R. $150 \mathrm{ml}$., phosphoric acid (sp.g. 1.75) $25 \mathrm{ml}$., distilled water $\omega$ $325 \mathrm{ml}$. The old and new techniques are of compared.
Folin and $W u$

$2 \mathrm{ml}$.

1. Blood filtrate + alkaline copper or standard

Heat in a boiling water-bath for exactly 6 minutes

2. Cool (2-3 minutes)

3. Add $2 \mathrm{ml}$. of phosphomolybdic reagent. Allow 2 minutes for reaction to take place.

4. Dilute with distilled water to total volume $12.5 \mathrm{ml}$. Mix and read in a colorimeter using a red filter.
3. Add $10 \mathrm{ml}$. of dilute phosphomolybdic reagent. After one minute mix and read $\frac{0}{\circ}$ in a colorimeter using $\varrho$ a red filter.
This technique not only eliminates the problem of fading but also shortens and simplifies the original method, so reducing opportunity for errors $\delta$ of technique. The danger of slight but significant $₹$ differences of temperature between standards and 0 unknown solutions at the stage of adding P.M.R. is greatly reduced, for the temperature of the? reaction is dominated by that of the P.M.R.

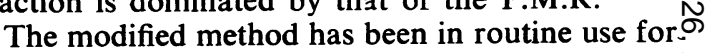
six months and has proved most satisfactory. $N$ Details are added as an appendix.

\section{Summary}

The density of colour in the Folin and $\mathrm{Wu} \stackrel{\text { }}{\bar{\complement}}$ method is directly proportional to the concentra-? tion of phosphomolybdic reagent (P.M.R.) as well as the concentration of reduced copper. It is also inversely proportional to the temperature of the $\frac{\mathbb{\Phi}}{\mathbb{\Phi}}$ mixture.

Initial colour production is immediate, buto change in concentration of the phosphomolybdic 
reagent or in the temperature of the mixture is followed by a slow change in density until equilibrium is reached.

The alkaline copper reagent and phosphomolybdic reagent form a photosensitive mixture. Exposure to daylight results in the production of a blue colour unrelated to the amount of reduced copper present.

Previous modifications introduced to improve colour stability are discussed and their mode of action considered. Although some are successful they add additional manipulations to the original technique.

A new modification to the original Folin and $\mathrm{Wu}$ method is described, which both obviates fading and simplifies the original technique.

I wish to thank Group Captain Stamm for his advice and guidance in the preparation of this paper, the Director General Medical Services for permission to publish, and Corporal Whyley for technical assistance.

\section{A P P E N D I X}

\section{Routine Procedure for Blood Glucose Estimation}

A "true glucose" (Haslewood and Strookman, 1939) method of protein precipitation is employed.

Reagents.-The following are required:

1. Isotonic Sodium Sulphate-Copper Sulphate Solution (prepared by mixing $320 \mathrm{ml}$. of $3 \% \mathrm{Na}_{2} \mathrm{SO}_{4} .10$ $\mathrm{H}_{2} \mathrm{O}$ with $30 \mathrm{ml}$. of $7 \% \mathrm{CuSO}_{4} 5 \mathrm{H}_{2} \mathrm{O}$.

\section{2. $10 \%$ Sodium Tungstate Solution.}

3. Alkaline Copper Reagent (Folin and Wu, 1920). This can be kept as two solutions, one containing the copper sulphate and the other sodium carbonate and tartaric acid. The reagent is then prepared freshly before use.

4. Dilute Phosphomolybdic Reagent.-This contains $150 \mathrm{ml}$. of phosphomolybdic reagent (Folin and Wu, 1920) and $25 \mathrm{ml}$. of phosphoric acid (sp.g. 1.75) in $500 \mathrm{ml}$. of distilled water.

5. Working Standard Glucose Solution, $2 \mathrm{mg} . \%$ in saturated benzoic acid solution.
Method.-Blood, $0.1 \mathrm{ml}$., is placed in $4.6 \mathrm{ml}$. cf isotonic sodium sulphate-copper sulphate solution, then $0.3 \mathrm{ml}$. of sodium tungstate is added, thoroughly mixed and centrifuged.

Supernatant fluid, $2 \mathrm{ml}$., is pipetted into a Folin and $\mathrm{Wu}$ tube, and $2 \mathrm{ml}$. of the standard glucose solution into a similar tube. Then $2 \mathrm{ml}$. of alkaline copper reagent is added to each, mixed, and stoppered with non-absorbent cotton wool. The mixtures are heated in a boiling water bath for exactly six minutes and rapidly cooled to room temperature. Two minutes are allowed for the tubes finally to reach this temperature, then $10 \mathrm{ml}$. of dilute phosphomolybdic reagent is added to each.

The solutions are mixed by two inversions and read in a colorimeter, using a red filter.

$$
\text { Calculation.- }\left(\frac{\text { Reading of unknown }}{\text { Reading of standard }} \times 1 \mathrm{co}\right) \mathrm{mg} . / 100 \mathrm{ml} \text {. }
$$

If the unknown is too deep to compare with the standard (reading above the equivalent of $180 \mathrm{mg}$. glucose per $100 \mathrm{ml}$.) dilute $1: 1$ with dilute phosphomolybdic reagent and multiply the answer by 2 .

A distilled water blank should be included once a day to check the condition of the copper reagent. Blank values are not subtracted from standard or test readings. Blank solutions are not used for zero setting of the colorimeter.

\section{REFERENCES}

Benedict, S. R. (1931). J. biol. Chem., 92, 141.

Fiorentino, M., and Giannettasio, G. (1940). J. Lab. clin. Med., 25, 866.

Fister, H. J. (1950). Manual of Standardized Procedures for Spectrophotometric Chemistry, Ed. I. Method D-10a, pp. 1-7. Standard Scientific Supply Corporation, New York

Folin, O. (1926). J. biol. Chem., 67, 357.

Folin, (1929). Ibid., 82, 83. (1929). Ibid., 82, 83. Ibid., 41, 367.

Harding, V. J., and Downs, C. E. (1933). Ibid., 101, 487.

Haslewood, G. A. D., and Strookman, T. A. (1939). Biochem. J., 33,920 .

King, E. J., and Garner, R. J. (1947). Journal of Clinical Pathology, i, 30 .

Lehmann, H., and Silk, E. (1952). Biochem. J., 50, xxxi.

Sahyun, M. (1936). J. Lab. clin. Med., 21, 1089.

Sobel, A. E. (1947). Quantitative Ultramicrochemistry in Clinical Laboratories, p. 9. Department of Biochemistry, Jewish Hospital of Brooklyn.

Thomson, D. L. (1946). Laboratory Manual for Biochemistry, p. 62. McGill University, Montreal.

Tonks, D. B. (1952). Amer. J. clin. Path., 22, 1009.

War Department Technical Manual (1946). Washington, T.M. 8-227, p. 198. 